DOSSIÊ TEMÁTICO: Formação inicial de professores em contextos escolares e binômio teoria/prática nos estágios supervisionados

do] https://doi.org/10.22481/rpe.v16i43.6778

\title{
OS REGISTROS DA AÇÃO DOCENTE NO PERÍODO DO ESTÁGIO SUPERVISIONADO: UMA EXPERIÊNCIA FORMATIVA
}

\author{
THE TEACHING ACTION RECORDS IN THE SUPERVISED PRACTICE PERIOD: \\ A FORMATIVE EXPERIENCE
}

\section{LOS REGISTROS DE LA ACCIÓN DOCENTE EN EL PERÍODO DE LA PRÁCTICA SUPERVISADA: UNA EXPERIENCIA FORMATIVA}

\author{
Elcimar Simão Martins \\ Universidade da Integração Internacional da Lusofonia Afro-Brasileira - Brasil
}

\author{
Tânia Maria Sousa França \\ Universidade Estadual do Ceará - Brasil
}

\begin{abstract}
Resumo: Os registros da ação docente se iniciam durante a formação inicial e fazem parte do cotidiano profissional do professor. $\mathrm{O}$ trabalho desenvolve-se a partir da seguinte questão: os registros da ação docente no período do estágio supervisionado podem ser considerados uma experiência formativa para professoras de Educação Infantil? Este estudo buscou, portanto, refletir sobre os registros da ação docente, no período do estágio supervisionado, como experiência formativa de professoras de Educação Infantil. A metodologia utilizada foi embasada na abordagem qualitativa, por meio de uma pesquisa documental exploratória, realizada nos diários de formação pertencentes às estagiárias de educação infantil ao realizarem o estágio em uma creche municipal na cidade de Fortaleza-CE. Os dados revelam que o conjunto dos diários de formação das alunas participantes dessa pesquisa constitui um panorama da realidade da ação docente no período de estágio supervisionado. Conclui-se que a escrita do vivenciado na escola e o momento de compartilhar essas experiências com os pares proporcionou um novo olhar sobre o vivido e a realidade escolar. Tal ação contribui para a formação dos sujeitos, pois é uma forma de articulação entre teoria e prática de forma reflexiva. Isso se dá pelo fato de que não se trata somente de relatar o que aconteceu, mas de se buscar compreender o vivido e à luz da teoria transformar o cotidiano a partir de uma reflexão sobre o seu fazer, gerando ação-reflexão-ação.
\end{abstract}

Palavras chave: Formação inicial docente. Estágio supervisionado. Diários de formação.

\begin{abstract}
The teaching action records begin during the initial training and they are part of the professional daily life of the teacher. The work develops from the following question: can the teaching action records in the supervised practice be considered a formative experience of the Early Childhood Education Teacher? This study has sought, therefore, to reflect on the teaching action records, in the supervised practice period, as a formative experience of the teacher during Early Childhood Education. The methodology used was based on the qualitative approach, through an exploratory documentary
\end{abstract}


research carried out in training diaries belonging to early childhood education interns when they were performing their practice at a municipal day care center in the city of Fortaleza-CE. The data reveal that the set of training diaries of the students participating in this research is an overview of the reality of teaching action in the supervised practice period. It was concluded that the writing about what was experienced in school and the moment of sharing these experiences with peers provided a new look over what it was lived and the school reality. This action contributes to the formation of the subjects, because it is a form of articulation between theory and practice in a reflexive way. This is due to the fact that it is not only a question of reporting what happened, but also try to understand what was lived and in the light of the theory transform daily life from a reflection on the way it is done, generating actionreflection-action.

Keywords: Initial teacher training. Supervised practice. Training diaries.

Resumen: Los registros de la acción docente comienzan durante la capacitación inicial y son parte de la rutina profesional del maestro. El trabajo se desarrolla a partir de la siguiente pregunta: ¿pueden los registros de la acción docente en el período de la pasantía supervisada considerarse una experiencia formativa del maestro de Educación Infantil? Este estudio buscó, por lo tanto, reflexionar sobre los registros de la acción docente, durante el período de la pasantía supervisada, como una experiencia formativa del maestro de Educación Infantil. La metodología utilizada se basó en el enfoque cualitativo, a través de una investigación documental exploratoria, realizada en los diarios de capacitación de los pasantes de educación infantil cuando realizaron la pasantía en una guardería municipal en la ciudad de Fortaleza-CE. Los datos revelan que el conjunto de diarios de capacitación de los estudiantes que participan en esta investigación constituye una visión general de la realidad de la acción docente en el período de prácticas supervisadas. Se concluye que la escritura de lo que se experimentó en la escuela y el momento de compartir estas experiencias con sus compañeros proporcionó una nueva mirada a la realidad vivida y la escuela. Dicha acción contribuye a la formación de los sujetos, ya que es una forma de articulación entre la teoría y la práctica de manera reflexiva. Esto se debe al hecho de que no se trata solo de informar lo que sucedió, sino de tratar de comprender lo que se ha vivido y a la luz de la teoría, transformando la vida diaria en función de una reflexión sobre sus acciones, generando acción-reflexiónacción.

Palabras clave: Formación inicial del profesorado. Prácticas supervisadas. Diarios de entrenamiento.

\section{Primeiros registros}

A última década do século XX é marcada mundialmente pelo movimento de valorização da formação e da profissionalização docente. As mudanças ocorridas na economia mundial repercutem diretamente nas políticas educacionais brasileiras. Diante disso, surgiram e continuam surgindo novas exigências, o que implica um novo fazer nas escolas e, consequentemente, novas demandas à formação do futuro professor.

A formação inicial docente, portanto, é um tema complexo e que vem sendo muito estudado, sobretudo após a promulgação da LDB No 9394/96, quando no seu artigo 62, eleva a formação de professores para o nível superior (BRASIL, 1996). Tal fato retrata a preocupação 
com a formação inicial dos professores para os primeiros anos da educação básica, especialmente, em relação à Licenciatura em Pedagogia, pois segundo as Diretrizes Curriculares Nacionais (2006), no Art. $2^{\circ}$, o curso é responsável pela formação inicial para o exercício da docência na Educação Infantil e nos anos iniciais do Ensino Fundamental (BRASIL, 2006).

Pesquisadores como Pimenta et al. (2017), Silvestre e Pinto (2017), Pedroso et al. (2019), Gatti (2010), por meio de suas pesquisas trazem uma discussão sobre a formação inicial, ponderando que "esses cursos, em sua maioria, não estão formando o pedagogo e, tampouco, um professor polivalente para a educação infantil e anos iniciais do ensino fundamental, pois sua formação se mostra frágil, superficial, generalizante, fragmentada, dispersiva e sem foco" (PIMENTA et al., 2017, p. 15).

Em sua essência, a formação inicial deve oportunizar a base do conhecimento pedagógico, proporcionando uma interligação real com as situações educativas, analisando-as, renovando-as e equilibrando teoria e prática (IMBERNÓN, 2011). A universidade, portanto, é responsável por disponibilizar ao futuro professor uma sólida formação inicial e favorecer os mecanismos para que ele compreenda o seu complexo papel social, pautado pelo compromisso com a qualidade da educação pública.

Com efeito, a formação inicial deve contribuir para a formação de professores criativos, hábeis para a resolução de problemas, solidários para o trabalho coletivo com vistas a garantir uma educação de qualidade aos discentes. Para tanto, cabe aos cursos de licenciatura mobilizar o futuro docente para trabalhar a partir de várias dimensões: a ética, a estética, a afetiva, a dos valores emocionais, a dos sentidos, além da cognitiva, obviamente (GHEDIN; ALMEIDA; LEITE, 2008).

Nesta perspectiva, Pimenta (2005), aponta para a importância da formação de um professor intelectual, crítico, reflexivo, o que implica na capacidade de pensar sobre a sua prática, de fazer uma autorreflexão de forma crítica e transformadora sobre a sua ação docente. Como instrumento dessa reflexão, os registros pedagógicos transformam-se em experiência formativa, na medida em que registram o cotidiano escolar e oferecem aos professores condições de se tornarem conscientes de suas escolhas epistemológicas, compreendendo porque agem de uma determinada forma, impulsionando-os para uma nova aprendizagem.

Escolhemos este tema para a presente investigação, pois a ação de registrar faz parte das nossas vidas, seja na atuação profissional, como professores de estágio supervisionado ou na trajetória acadêmica, ao usarmos o registro como apoio para estudos e reflexões, nos levando a 
questionar: quais os saberes necessários para um bom desempenho do professor? Como o professor avalia, reflete sobre sua prática? O docente tem o hábito de registrar a sua ação? Os registros pedagógicos podem ser considerados espaços-tempos de formação? Tais indagações nos levaram à questão norteadora desse estudo, qual seja: os registros da ação docente no período do estágio supervisionado podem ser considerados uma experiência formativa para professoras de Educação Infantil?

Nesse contexto, o presente artigo objetiva refletir sobre os registros da ação docente, no período do estágio supervisionado, como uma experiência formativa de professoras $^{1}$ de Educação Infantil.

Essa investigação tem como base uma abordagem qualitativa de pesquisa, uma vez que esta, "trabalha com o universo de significados, motivos, aspirações, crenças, valores e atitudes" (MINAYO, 2001, p. 24), por meio de uma pesquisa documental exploratória realizada nos diários de formação pertencentes a seis (6) estagiárias de educação infantil, ao realizarem o estágio supervisionado em uma creche municipal de Fortaleza-CE.

Para tanto, além da legislação educacional, nos apoiamos nos estudos de Pimenta e Lima (2017), Pimenta (2005), Lima (2012), Imbernón (2011), quando discutem sobre o estágio supervisionado e a formação inicial docente. Tomamos por base as ideias de Ostetto (2011; 2008) e Freire (1998) ao defenderem o registro como forma de pensar na e sobre a prática, favorecendo uma reflexão que gera trans-forma-ação. Outros estudiosos como Warschauer (2001; 2002), Josso (2004), Nóvoa (2010), Souza (2006), Lopes (2009), dentre outros, também fazem parte do aporte teórico, ao defenderem a importância dos registros para que se possa compreender a prática e ao mesmo tempo buscam pesquisar sobre os registros como espaço de formação. Nos apoiamos ainda nas ideias de Larrosa (2014), ao refletir sobre o conceito de experiência, contribuindo para corroborar o nosso pressuposto dos registros pedagógicos como experiência formadora. Diante do exposto, nos reportamos a Warschauer (2002, p. 61) quando afirma que "registrar a própria prática pode ser um rico instrumento de trabalho para o professor que busca reconstruir os conhecimentos junto com os alunos, porque o retrato do vivido proporciona condições especiais para o ato de refletir".

Com o intuito de pensar sobre os registros da ação docente, no período do estágio supervisionado como experiência formativa, partimos da concepção de que formação é composta de 'forma' + 'ação', trazendo na sua essência algo de permanente, que garante como

\footnotetext{
${ }^{1}$ Usamos a palavra no feminino por considerarmos que ainda prevalece na educação Infantil docentes do gênero feminino, como é o caso das seis participantes dessa investigação.
} 
diz Nóbrega-Therrien (2009), a "racionalidade pedagógica", ou seja, a forma singular de cada pessoa articular a sua compreensão e seus saberes, como se situa no mundo. Traz ainda algo dinâmico, pois ação nos reporta a movimento, não um movimento a esmo, mas reflexivo, considerando ação na perspectiva de Sousa e França (2007), como algo complexo e situado, que envolve vários elementos interligados, como: o contexto onde ocorre, o objetivo, as pessoas, os meios para que se desenvolva; sendo essa ação sempre cheia de simbologia e dramaticidade por incluir conflito, propósito, reflexão e escolha. Logo, a formação é compreendida, por nós, na perspectiva de desenvolvimento profissional, ou seja, como um processo pessoal, permanente, contínuo e inconcluso, como defende Freire (1998) e não como algo estático, que acontece em um determinado momento da vida.

Desta forma, trazemos a relevância do registro como uma ação que visa à qualificação do fazer pedagógico e da (auto) formação dos educadores (OSTETTO, 2011), porque no diário se registra aquilo que ouvimos, vimos, sentimos, fazemos e experienciamos no estágio supervisionado, considerando que "Escrever sobre si é auto-revelar-se, é um recurso privilegiado de tomada de consciência de si mesmo, pois permite "atingir um grau de elaboração lógica e de reflexibilidade", de forma mais acabada do que na expressão oral" (CATANI, 2000, p. 41-42).

Zabalza (2004) corrobora com essa reflexão ao anunciar que o ato de escrever sobre as ações que ocorrem no diário oferece mais clareza sobre os fatos vividos e é possível retornar sempre que necessário para rever o que foi feito de forma analítica. Esse autor elenca diversas modalidades de diários, dentre elas a modalidade reflexiva, quando a escrita pretende aclarar as próprias ideias sobre os temas trazidos no texto. Nessa perspectiva, Alarcão (2011), defende que esse processo seja acompanhado por uma metarreflexão sistematizadora das aprendizagens ocorridas, pois assim vai atingir um alto grau formativo.

Ao buscarmos compreender os registros como experiência formadora é relevante anunciarmos que estamos embasados na ideia de experiência de Larrosa (2014) quando afirma que

A experiência é o que nos passa, o que nos acontece, o que nos toca. Não o que se passa, não o que acontece, ou o que toca. A cada dia se passam muitas coisas, porém, ao mesmo tempo, quase nada nos acontece. Dir-se-ia que tudo o que se passa está organizado para que nada nos aconteça. [...] Nunca se passaram tantas coisas, mas a experiência é cada vez mais rara (LARROSA, 2014, p. 18). 
Tomamos por base ainda o conceito de experiência formadora de Josso (2004, p. 48) quando argumenta que uma experiência é formadora quando há "uma articulação conscientemente elaborada entre atividade, sensibilidade, afetividade e ideação". Assim, podemos afirmar que o registro por si só não garante a experiência formadora, porque esta requer condições de abertura sensível ao que está sendo vivido e registrado, de modo que não seja apenas um acontecimento, uma técnica, mas uma aprendizagem que

[...] articula, hierarquicamente: saber-fazer e conhecimentos, funcionalidade e significação, técnicas e valores num espaço-tempo que oferece a cada um a oportunidade de uma presença para si e para a situação, por meio da mobilização de uma pluralidade de registros (JOSSO 2004, p. 39).

Nessa perspectiva, defendemos os registros da ação docente realizados no estágio supervisionado como experiência formativa, como algo que passou por cada um, que aconteceu para cada um, que transpassou cada um no sentido de terem vivido a formação de corpo inteiro, pois articularam na atividade narrativa sensibilidade, criatividade, afetividade e concepções.

Lembramos que, ao realizarem o registro do vivido em forma de narrativa, as estagiárias vão narrando não mais o real, mas aquilo que elaboraram acerca do que aconteceu, possibilitando uma reflexão sobre o que foi feito, como foi feito e para que e quem foi feito. Por isso, compreendemos que a escrita (auto) biográfica constitui-se em uma possibilidade de ressignificação das histórias da docência.

Assim, para darmos conta dessa reflexão teórico-prática sobre os registros da ação docente durante o estágio supervisionado na licenciatura em Pedagogia, o presente artigo está organizado conforme segue. Além dessa seção introdutória, intitulada como Primeiros registros, apresentamos mais três seções: a primeira, apresenta algumas reflexões preliminares que subsidiam um olhar conceitual sobre o tema; a segunda, descreve uma análise dos diários de formação com alunas estagiárias da educação infantil. Por fim, tecemos reflexões acerca da contribuição dos registros para a formação inicial de professores.

\section{Significados do ato de registrar}

Ao longo do tempo, o homem sempre procurou registrar suas ações, seus sentimentos, como podemos constatar através das imagens desenhadas nas cavernas, pois como afirma Warschauer (2002, p. 61), "registrar é deixar marcas. Marcas que retratam uma história de vida". 
Na educação, o registro da ação docente tornou-se nas últimas décadas, motivo de muitos estudos e reflexões, fato observado de maneira geral, por meio dos documentos oficiais de orientação pedagógica e na literatura nacional e internacional, por ser considerada uma atividade de grande valor para a formação dos professores, pois permite uma reflexão sobre o seu fazer, gerando ação-reflexão-ação.

Desta forma, é relevante trazermos para esta reflexão o significado do registro nos documentos oficiais: na Lei de Diretrizes e Bases da Educação - LDB 9394/96 (BRASIL, 1996), nos Referenciais Curriculares da Educação Infantil (BRASIL, 1998), nas Diretrizes Curriculares Nacionais para a formação inicial em nível superior (BRASIL, 2015) e na Base Nacional Comum Curricular - BNCC (BRASIL, 2017).

Na LDB 9394/96, Seção II - da Educação Infantil, Art. 31, o registro é considerado um instrumento para a avaliação: "Na educação infantil a avaliação far-se-á mediante acompanhamento e registro do seu desenvolvimento, sem o objetivo de promoção, mesmo para o acesso ao ensino fundamental" (BRASIL, 1996).

No Referencial Curricular Nacional para a Educação Infantil (1998), no volume 1, o registro aparece vinculado à observação e à avaliação formativa, mas também como apoio da prática, especialmente ao planejamento educativo.

A observação e o registro se constituem nos principais instrumentos de que o
professor dispõe para apoiar sua prática. Por meio deles o professor pode
registrar, contextualmente, os processos de aprendizagem das crianças; a
qualidade das interações estabelecidas com outras crianças, funcionários e
com o professor e acompanhar os processos de desenvolvimento obtendo
informações sobre as experiências das crianças na instituição. Esta observação
e seu registro fornecem aos professores uma visão integral das crianças ao
mesmo tempo que revelam suas particularidades. São várias as maneiras pelas
quais a observação pode ser registrada pelos professores. A escrita é, sem
dúvida, a mais comum e acessível. O registro diário de suas observações,
impressões, ideias etc. pode compor um rico material de reflexão e ajuda para
o planejamento educativo. Outras formas de registro também, podem ser
consideradas, como a gravação em áudio e vídeo; produções das crianças ao
longo do tempo; fotografias etc. (BRASIL, 1998, p. 58-59).

De modo equivalente, ocorre nas Diretrizes Curriculares Nacionais para a Educação Infantil (BRASIL, 2010), quando no tópico 12 sobre avaliação, coloca que "as instituições de Educação Infantil devem criar procedimentos para o acompanhamento do trabalho pedagógico e para avaliação do desenvolvimento das crianças”, devendo garantir a utilização de múltiplos registros tanto por parte do professor como dos alunos. 
Nas Diretrizes Curriculares Nacionais para a formação inicial em nível superior (BRASIL, 2015), o Artigo $7^{\circ}$, item IX do Parágrafo Único, anuncia que o PPC deve abranger diferentes características e dimensões da iniciação à docência, dentre elas a "sistematização e registro das atividades em portfólio ou recurso equivalente de acompanhamento".

A Base Nacional Comum Curricular - BNCC, sobre os registros, coloca que

O acompanhamento da aprendizagem e do desenvolvimento dá-se pela observação da trajetória de cada criança e de todo o grupo - suas conquistas, avanços, possibilidades e aprendizagens. Por meio de diversos registros, feitos em diferentes momentos tanto pelos professores quanto pelas crianças (como relatórios, portfólios, fotografias, desenhos e textos), é possível evidenciar a progressão ocorrida durante o período observado, sem intenção de seleção, promoção ou classificação de crianças em "aptas" e "não aptas", "prontas" ou "não prontas", "maduras" ou "imaturas" (BRASIL, 2017, p. 35).

Podemos perceber nesses documentos que o registro está relacionado à avaliação, como instrumento de apoio e acompanhamento do desenvolvimento das crianças e da atuação profissional dos professores. Não negamos essa possibilidade, mas queremos ressaltar a relevância da orientação como acompanhamento do trabalho pedagógico, mesmo sem explicitar a dimensão reflexiva dos registros da prática docente, como defende Freire (1996, p. 6) ao colocar que "este aprendizado do registro é o mais poderoso instrumento de construção da consciência pedagógica e política do educador”.

Assim, consideramos que registrar não se restringe a uma técnica simplesmente, mas significa deixar marcas, ou seja, é criação, recriação e memória da própria vida (WARSCHAUER, 2002). Para isso é necessário um olhar sensível e pensante, que nos permita observar não somente o que está posto, mas ver além das aparências. Freire (1993, p. 68), refletindo sobre isso, pontua:

Precisamos exercitar a capacidade de observar, registrando o que observamos. Mas registrar não se esgota no puro ato de fixar com pormenores o observado tal qual para nós se deu. Significa também arriscar-nos a fazer observações críticas e avaliativas a que não devemos, contudo, emprestar ares de certeza.

No caso da ação docente, compreendemos que o registro é uma forma de articular teoria e prática de forma reflexiva. Por isso é pertinente indagar: para que registrar? Ostetto (2011, p. 13) corrobora com esta reflexão, pontuando que

Por meio do registro travamos um diálogo com nossa prática, entremeando perguntas, percebendo idas e vindas, buscando respostas que vão sendo elaboradas no encadeamento da escrita, na medida em que o vivido vai se tornando explícito, traduzido e, portanto, passível de reflexão. 
Ainda, defende a mesma autora, que o "ato de registrar poderá ajudar no exercício de 'desabituar-se' [...] limpar os olhos, clarear a visão”. (OSTETTO, 2011, p. 22), ou seja, contribui para que professores possam olhar de outro modo para o seu fazer docente.

Freire (1996) defende que registramos o que nos serviu de elemento de formação. Corrobora com esse pensamento, Warschauer (2002, p. 63), quando diz que "o registro permite que vejamos a historicidade do processo de construção dos conhecimentos, porque ilumina a história vivida e auxilia a criação do novo a partir do velho". A referida autora ainda comunga com Freire (1996) no que diz respeito à socialização ao refletir que

A escrita da experiência, quando é lida por outros, leva-nos a sair de nós mesmos para sermos capazes de partilhar pensamentos, provocando a passagem do implícito para o explícito. [...] Assim a escrita para o outro é, ao mesmo tempo, formadora da capacidade de partilhar. Inicia-se com uma implicação grande, construindo um afastamento. É um movimento formador porque distanciador: nosso olhar recebe um outro reflexo (WARSCHAUER, 2001, p. 190).

Compreendemos, então, que na educação registramos para sistematizar a ação pedagógica de uma forma reflexiva, porque não se trata apenas de descrever, narrar o que aconteceu, mas de se tentar compreender o que passou e, à luz da teoria, transformar o cotidiano e a si mesmo. Podemos afirmar ainda que registramos para garantir a autoria do professor, o comprometimento com a própria prática. Registramos, também, para guardar o vivido em forma de documentos para poder ser revisitado em outras oportunidades.

Neste momento uma nova indagação se faz presente: como registrar? Compreendendo o registro como criação, podemos afirmar como diz Ostetto (2011), que não existe uma regra, uma receita. O registro é algo pessoal do professor, cada um vai colocar a sua marca, deixar fluir o seu estilo, pois estará registrando emoções, acontecimentos, impressões, aprendizagens e esse caminho é individual. Cada professor faz seus registros com base nas suas referências e histórias de vida e pode ser concretizado por meio de várias linguagens e diversidades de formas.

Considerando as ideias de Ostetto (2001) e Lopes (2009), nesse estudo, serão utilizados como análise os registros realizados pelos estudantes no formato de diário de formação. Nesse sentido,

[...] o diário traz consigo grande implicação pessoal, o que, para o autor, o converte em um documento pessoal e autobiográfico ao lado de outros, como história de vida, cartas, diários íntimos, biografias. No diário expressa-se não apenas o professor, mas também a pessoa, seus anseios, dúvidas, valores e crenças (LOPES, 2009, p. 31). 
Ostetto (2001, p.19-20) nos diz o seguinte ao se referir ao diário enquanto instrumento de registro:

\begin{abstract}
No espaço educacional o registro é, para o educador uma espécie de diário, que pode bem lembrar os diários de bordo ou os diários dos adolescentes, nos quais são anotados fatos vividos, sentimentos, impressões, confissões. Quanto ao diário do professor, num âmbito da prática pedagógica, vai muito além disso: constitui-se em um lugar de reflexões sistemáticas constantes, um espaço onde o professor conversa consigo mesmo, anota leituras, revê encaminhamentos, avalia atividades realizadas, documenta o percurso de sua classe. Um documento com a história do grupo dos avanços do próprio professor.
\end{abstract}

A partir dessas ideias, definimos diário de formação como uma escrita detalhada e reflexiva do cotidiano escolar, apresentando aprendizagens, dificuldades e desafios, tanto didáticos quanto psicossociais, destacando o que os estudantes aprenderam e o que essa experiência significou para a formação, realizando também um diálogo com autores que podem ajudar na reflexão.

\title{
O que dizem os diários de formação das estagiárias
}

Antes de adentrarmos ao que dizem os diários é importante pontuarmos que compreendemos o estágio supervisionado como espaço-tempo de articulação teoria e prática, fundamental para a reflexão e análise do fazer profissional, na construção da identidade docente.

Defendemos que o estágio supervisionado não deve ocupar apenas o último semestre do curso, como alerta Lima (2012), ou seja, apenas com o momento onde será realizada a prática, cumprindo, assim, apenas uma questão burocrática. De modo contrário, o estágio deve permitir que o professor indague, pergunte sobre o que está vendo e vivenciando, buscando superar a compreensão dual " [...] que o reduz à aplicação de saberes de forma descontextualizada, para ser entendido como oportunidade de aproximação crítica com a realidade, de forma que esta seja entendida no âmbito das relações que envolvem a escola no contexto social mais amplo" (PIMENTA; LIMA, 2017, p. 37).

Com efeito, o estágio supervisionado deve ser compreendido como espaço de pesquisa, que favorece a interação com o cotidiano escolar de uma maneira reflexiva, compreendendo que o cotidiano pode acomodar ou transformar, sendo a pergunta uma mediação para o movimento de reflexão acontecer (ALMEIDA, 2000). 
Outra reflexão que queremos trazer neste momento é sobre a palavra formação, que traz no seu cerne a forma como a ação é realizada. A partir disso, podemos colocar que o estágio também traz como subsídio para a formação docente a possibilidade de exercitar uma forma de ação e de ver uma forma de ação sendo exercitada, podendo fazer o movimento de açãoreflexão-ação.

A escrita dos diários de formação permite que essa ação refletida aconteça porque o aluno ao escrever sua prática e sobre sua prática revive o vivido de outra perspectiva. Os diários de formação analisados foram escritos por seis estagiárias de educação infantil, numa creche municipal de Fortaleza-CE, por ocasião da disciplina de estágio supervisionado em uma IES pública cearense.

Um primeiro ponto analisado se refere ao caráter individual do diário, uma vez que são todos diferentes. Podemos perceber a individuação de cada um na apresentação e no estilo da escrita. Temos escritas manuais, em cadernos enfeitados; temos escritas computadorizadas, imitando escritas manuais. Encontramos texto mais formal, outros mais sucintos, com uma linguagem mais coloquial. Isso evidencia o que diz Ostetto (2011, p. 25):

Tenho afirmado que o registro é espaço específico de cada educador, é pessoal, particular; seu caráter é individual, como os "diários de adolescente", pois é também uma espécie de "confissão", de "testemunho". Não pode ser concebido, nem utilizado, como forma de controle, de qualquer coordenador ou supervisor.

Outro aspecto diz respeito à estrutura do texto. Todas as estagiárias optaram em descrever o vivido na sequência das aulas e dos dias do estágio na escola, pois o diário não se limitou a ida à escola, mas deveria apresentar uma reflexão mais geral do processo formativo de cada estagiária desde o primeiro dia de aula. Observamos, entretanto, que nenhuma estudante ousou fazer de forma diferente, por temática, por exemplo. Todas mantiveram a linearidade, embora, às vezes, até com pouca escrita.

Surgem, então, algumas indagações: porque as estagiárias agiram assim? Estão sob o efeito ainda da perspectiva positivista que só admite uma única forma de ver as coisas? Zabalza (2004, p. 13) comenta que

Os diários não têm por que ser uma atividade diária. Cumprem perfeitamente sua função [...] mesmo que sua periodicidade seja menor: duas vezes por semana, por exemplo, variando os dias para que a narração seja mais representativa. O importante é manter uma certa linha de continuidade na coleta e na redação das narrações (enfim, que não seja uma atividade intermitente, feita apenas de vez em quando e sem nenhuma sistematicidade). 
Hess (2006, p. 91), por sua vez, diz que o "diário é redigido dia a dia". Sua recomendação não se resume a uma sequência rígida, posto que a escrita do diário "não é uma escrita posterior, mas um escrito do momento". Compreendemos que o autor alerta para que a escrita seja feita logo para garantir a memória do que aconteceu e os sentimentos experienciados, pois depois fica uma atividade mecânica, sem sentimento de pertencimento. Este fato foi percebido em alguns diários analisados quando o aluno escrevia: "Vivência em sala com as crianças. Foi uma manhã bastante proveitosa, engraçada, instigante e curiosa" (Diário 1).

Partindo dessas ideias fomos analisar se os diários de formação apresentavam uma reflexão sobre as práticas descritas ou se estavam limitados à descrição do acontecido. Verificamos que esta última hipótese é a mais recorrente, como fica evidente na escrita no Diário 1: "Acredito que minha falta de experiência em sala foi o que mais atrapalhou". A estagiária até identifica o que pode ter atrapalhado o seu desempenho na sala de aula, mas não tece nenhuma reflexão sobre isso, apenas constata. Concordamos com Freire (1998, p. 44) quando ensina que "quanto mais me assumo como estou sendo e percebo a ou as razões de ser de porque estou sendo assim, mas me torno capaz de mudar, de promover-me, no caso, do estado de curiosidade ingênua para o de curiosidade epistemológica".

Percebemos, também, algumas escritas que apresentam o exercício da reflexão sobre a sua prática, sua forma de agir, seus medos, mesmo num nível ainda do senso comum, como podemos apreciar, mas ainda não é uma constante.

Particularmente os momentos que antecederam as minhas regências foram de grande anseio. Ficava pensativa, um pouco preocupada e criando várias expectativas. Meu maior medo era não conseguir realizar de forma satisfatória aquilo que havia proposto (Diário 4).

Esta seria a minha primeira experiência com a educação infantil. O que fazer? Como me comportar? Como lidar com 15 crianças ao mesmo tempo? Estas perguntas eram essenciais para minha formação (Diário 5).

Ostetto (2017, p. 21) nos ajuda a pensar sobre essa escrita reflexiva, pontuando que "ao registrarem e refletirem sobre o conteúdo registrado, professoras e professores, apropriando-se de sua história, ensaiam autoria”. Uma autoria que para nós seria um ensaio de experiência formadora, pois percebemos pelas escritas que aconteceu uma articulação entre a atividade vivida e registrada, a sensibilidade, a afetividade e a ideação, mesmo sendo esta última ainda muito elementar. 
Por fim, as estagiárias expressaram nas escritas uma preocupação com a sua formação, evidenciando que não se resume aos momentos de sala de aula, mas que aprendem e se formam também com a troca de experiência nos momentos de compartilhamento na universidade e ampliam o olhar para ver as vivências diárias como fontes de pesquisa, apresentando assim o estágio como pesquisa.

Para mim a conversa foi muito produtiva (ao se referir a troca de experiência na sala), pois pude perceber (embora já tivesse quase certeza) de que apenas a teoria que aprendemos não é o suficiente para que consigamos tomar a frente de uma sala de aula com segurança (Diário 2).

A estagiária que escreveu o Diário 2 revela a importância do encontro entre a teoria e a prática para a formação de futuros docentes, favorecendo a compreensão de que "o estágio enquanto momento de articulação teoria-prática é formador da dimensão científica/técnica, política, ética e estética do futuro professor. Compreende-se que é nesse tempo/espaço que o professor em formação constrói sua identidade profissional” (GHEDIN; OLIVEIRA; ALMEIDA, 2015, p. 37).

Nesse sentido, apoiados em Pimenta e Anastasiou (2010, p. 84), trazemos a importância do estágio como pesquisa, articulando conhecimento específico e pedagógico, compreendendo que "a especificidade da formação pedagógica, tanto inicial como contínua, não é refletir sobre o que se vai fazer, nem sobre o que se deve fazer, mas sobre o que se faz". Assim, trazemos a compreensão da estagiária que escreveu o Diário 3:

Eu penso que cada um de nós deve zelar pela sua formação da melhor forma possível. Transformar as nossas vivências diárias em fontes de pesquisa. Não nos limitarmos somente ao teórico e tampouco a prática, mas procurar unificar e aos poucos construindo a sua própria didática (Diário 3).

O estágio visto em uma perspectiva com/como pesquisa "possibilita aos estudantes compreenderem os limites e as possibilidades das práticas de ensino como questões de pesquisa a serem problematizadas no diálogo entre os sujeitos envolvidos e os conhecimentos teóricos já produzidos" (MARTINS; ALMEIDA, 2018, p. 3). Tem-se, portanto, uma compreensão de estágio supervisionado que ultrapassa a mera compreensão de atividades como observação e regência, assumindo uma postura crítica de análise das práticas pedagógicas.

Com relação aos registros da ação docente, no período do estágio supervisionado, como elemento de formação de professoras de Educação Infantil, as estagiárias não explicitaram essa compreensão, apenas uma aluna escreveu no seu diário, nas considerações finais, que os registros feitos de todas as aulas foram atividades relevantes para a formação dela tanto pessoal 
quanto profissional e justificou dizendo: "afinal em nossa vida precisamos planejar e refletir sobre os acontecimentos" (Diário 6).

Percebemos que, mesmo sem esse reconhecimento consciente, somente o fato de reescrever o vivido e compartilhar essa escrita na sala de aula com os demais colegas já favorece uma reflexão sobre aquele agir, implicando na sua formação, podendo ser caracterizado como uma experiência formativa.

O estágio supervisionado, portanto, aproxima professores em processo de formação com o contexto em que irão atuar, problematizando o ensino e a aprendizagem, possibilitando ainda a reflexão sobre a prática. Diante do exposto, compreendemos que a formação inicial, em especial, o estágio supervisionado, deve proporcionar a reflexão sistemática das práticas pedagógicas, com vistas ao desenvolvimento não apenas do pensamento, mas, sobretudo da ação refletida.

\section{Considerações finais}

A partir do objetivo desse artigo, qual seja, refletir sobre os registros da ação docente, no período do estágio supervisionado, como uma experiência formativa de professoras de Educação Infantil podemos dizer que o conjunto dos diários de formação das alunas participantes dessa pesquisa constitui um panorama da realidade da ação docente no período de estágio supervisionado. A investigação sinaliza que os diários assumem um caráter de individualidade, pois cada estagiária escreveu à sua maneira, deixando fluir o seu estilo, seja na apresentação estética ou na própria escrita, apresentando uma linguagem mais coloquial ou formal.

De uma maneira geral, as participantes da pesquisa descreveram as experiências vividas de acordo com a sequência das aulas, seguindo a ordem cronológica do estágio supervisionado e limitando-se a relatos da ida à instituição investigada. Por outro lado, convém salientar que a atividade consistia em uma análise mais geral do processo formativo dos sujeitos desde o primeiro dia de aula.

A pesquisa sinalizou ainda que grande parte dos registros focou na descrição do acontecido. Apenas algumas estagiárias refletiram sobre o vivido, ponderando sobre sua maneira de agir.

Um achado relevante é que as estudantes não explicitaram se os registros da ação docente no período do estágio podem ser considerados uma experiência formativa para elas. 
Somente uma estagiária trouxe nas considerações finais de seu trabalho que os registros das aulas foram relevantes para a sua formação pessoal e profissional.

Por outro lado, constatamos que embora as estudantes não tenham verbalizado as contribuições dos registros para a sua formação, a escrita do que foi vivenciado na escola e o momento de compartilhar essas experiências com os seus pares proporcionou um novo olhar sobre o vivido e a realidade escolar. Tal ação contribui para a formação dos sujeitos, pois é uma forma de articulação da teoria e prática de forma reflexiva.

Isso se dá pelo fato de que não se trata somente de relatar o que aconteceu, mas de se buscar compreender o vivido e, à luz da teoria, transformar o cotidiano a partir de uma reflexão sobre o seu fazer, gerando ação-reflexão-ação.

Por fim, esperamos que esta reflexão contribua para que os registros possam ser incluídos na formação inicial de professores, compreendendo que ao gerar uma reflexão sobre a ação docente pode contribuir com a melhoria da educação, especialmente, da educação infantil.

\section{REFERÊNCIAS}

ALARCÃO, Isabel. Professores reflexivos em uma escola reflexiva. 8. ed. São Paulo: Cortez, 2011.

ALMEIDA, Custódio Luís Silva de. O cotidiano. Revista de Educação AEC, nº 117, 2000.

BRASIL. Resolução CNE/CP No 1, de 15 de maio de 2006. CNE/CP. Brasília: MEC, 2006.

BRASIL. Lei de Diretrizes e Bases da Educação Nacional: Lei n ${ }^{\circ}$ 9394/96 de 20 de dezembro de 1996. Brasília: MEC, 1996.

BRASIL. Base Nacional Comum Curricular. Brasília: MEC, 2017.

BRASIL. Ministério da Educação. CNE/CEB. Diretrizes Curriculares Nacionais para a Educação Infantil. Brasília, 2010.

BRASIL. MEC/SEF. Referencial Curricular Nacional para a Educação Infantil. Brasília, 1998, v.1, v. 2, v. 3.

BRASIL. Resolução CNE/CP no 2, de $1^{\circ}$ de julho de 2015. Define as Diretrizes Curriculares Nacionais para a formação inicial em nível superior. Brasília: MEC, 2015.

CATANI, Denice Barbara; BUENO, Belmira Oliveira; SOUSA, Cynthia Pereira; SOUZA, Maria Cecília Cortez Christiano de. Docência, Memória e Gênero: estudos sobre formação. São Paulo: Escrituras, 2000. 
FREIRE, Madalena. (org.) Observação, registro, reflexão: instrumentos metodológicos I. 2. ed. São Paulo: Espaço Pedagógico, 1996.

FREIRE, Paulo. Pedagogia da Autonomia: saberes necessários à prática educativa. São Paulo: Paz e Terra, 1998.

FREIRE, Paulo. Professora, sim; tia, não: cartas a quem ousa ensinar. São Paulo, Olho D’Agua, 1993.

GATTI, Bernadete. Formação de professores no Brasil: Características e problemas. Educ. Soc., Campinas, v. 31, n. 113, p. 1355-1379, out.-dez. 20101355 Disponível em http://www.cedes.unicamp.br/

GHEDIN, Evandro; ALMEIDA, Maria Isabel de Almeida; LEITE, Yoshie Ussami Ferrari. Formação de Professores: Caminhos e Descaminhos da Prática. Brasília: Líber Livro, 2008.

HESS, Remi. Momento do diário e diário dos momentos. In: SOUZA, Elizeu Clementino; ABRAHÃO; Maria Helena Menna Barreto (orgs.). Tempos, narrativas e ficções: a invenção de si. Porto Alegre: EDIPUCRS, 2006.

IMBERNÓN, Francisco. Formação docente e profissional: formar-se para a mudança e a incerteza. São Paulo: Cortez, 2011.

JOSSO, Marie-Christine. Experiência de vida e formação. São Paulo: Cortez, 2004.

LARROSA, Jorge. Tremores: escritos sobre experiência. 1. ed. Belo Horizonte: Autêntica Editora, 2014.

LIMA, Maria Socorro Lucena. Estágio e aprendizagem da profissão docente. Brasília: Liber Livro, 2012

LOPES, Amanda Cristina Teagno. Educação Infantil e registro de práticas. São Paulo: Cortez, 2009.

MARTINS, Elcimar Simão; ALMEIDA, Sinara Mota Neves de. Travessias Guiadas: o Estágio Supervisionado na Universidade da Integração Internacional da Lusofonia AfroBrasileira (UNILAB). In: Anais do XIX ENDIPE. Bianual, Volume 1, Número 40. Salvador: UFBA, 2018.

MINAYO, Maria Cecília de Souza (Org.). Pesquisa Social. Teoria, método e criatividade. 18 ed. Petrópolis: Vozes, 2001.

NÓBREGA-THERRIEN, Silvia Maria. Formação para além do ensino na docência universitária: reflexões ancoradas na formação cidadã. In: SALES, José Albio Moreira. Docência e Formação de professores: novos olhares sobre temáticas contemporâneas. Fortaleza: EdUECE, 2009. 
NÓVOA, Antonio; FINGER, Mathias. O método (auto)biográfico e a Formação. Natal, RN: EDUFRN; São Paulo, 2010.

OSTETTO, Luciana Esmeralda; OLIVEIRA, Eloisa Raquel; MESSINA, Virginia Silva. Deixando marcas... A prática do registro do cotidiano da educação infantil. Florianópolis: Cidade Futura, 2001.

OSTETTO, Luciana Esmeraldo. Observação, registro, documentação: nomear e significar as experiências In: OSTETTO, Luciana Esmeraldo. (Org.) Educação infantil: saberes e fazeres da formação de professores. 5. ed. São Paulo: Papirus, 2011.

OSTETTO, Luciana. (Org.) Registros na Educação Infantil: pesquisa e prática pedagógica. Campinas, SP: Papirus, 2017.

PEDROSO, Cristina Cinto Araújo et al. (Orgs.). Cursos de Pedagogia: inovações na formação de professores polivalentes. 1. Ed. - São Paulo: Cortez, 2019.

PIMENTA, Selma Garrido. Formação de professores: identidade e saberes da docência. In: PIMENTA, Selma Garrido et al. (Org.). Saberes pedagógicos e atividade docente. 4. ed. São Paulo: Cortez, 2005.

PIMENTA, Selma Garrido; LIMA, Maria Socorro Lucena. Estágio e docência. 8. ed. São Paulo: Cortez, 2017.

PIMENTA, Selma Garrido; FUSARI, José Cerchi; PEDROSO, Cristina Cinto Araujo; PINTO, Umberto de Andrade. Os cursos de licenciatura em pedagogia: fragilidades na formação inicial do professor polivalente. Educ. Pesqui., São Paulo, v. 43, n. 1, p.15-30, jan./mar. 2017.

PIMENTA, Selma Garrido; ANASTASIOU, Léa das Graças Camargos. Docência no ensino superior. 4. ed. São Paulo: Cortez, 2010.

SILVESTRE, Magali Aparecida; PINTO, Umberto de Andrade. (Orgs) Curso de pedagogia: avanços e limites após as Diretrizes Curriculares Nacionais. São Paulo: Cortez, 2017.

SOUSA, Maria do Socorro; FRANÇA, Tânia Maria de Sousa. Diversidade de ações educativas: formar, formando-se. Fortaleza: Encaixe, 2007.

SOUZA, Clementino Elizeu. O conhecimento de si: estágio e narrativas de formação de professores. Rio de Janeiro: DP\&A: Salvador: UNEB, 2006.

WARSCHAUER, Cecília. A roda e o registro; uma parceria entre professor, alunos e conhecimento. 4. ed. Rio de Janeiro: Paz e Terra, 2002.

WARSCHAUER, Cecília. Rodas em Rede: oportunidades formativas na escola e fora dela. Rio de Janeiro: Paz e Terra, 2001.

ZABALZA, Miguel A. Diários de aula: contributo para o estudo dos dilemas práticos dos professores. Porto: Porto Editora, 2004. 


\section{SOBRE OS AUTORES:}

\section{Elcimar Simão Martins}

Pós-Doutor em Educação pela Universidade de São Paulo (USP); Doutor em Educação pela Universidade Federal do Ceará (UFC); Professor na Universidade da Integração Internacional da Lusofonia Afro-Brasileira - Brasil; Mestrado Profissional em Ensino e Formação Docente (PPGEF UNILAB-IFCE); Mestrado Acadêmico em Sociobiodiversidade e Tecnologias Sustentáveis (MASTS UNILAB); Programa de Pós-Graduação em Educação (PPGE UECE); líder do Grupo de Estudos e Pesquisas sobre Educação, Diversidade e Docência - EDDocência; E-mail: elcimar@unilab.edu.br

iD http://orcid.org/0000-0002-5858-5705

\section{Tânia Maria Sousa França}

Doutora em Educação pela Universidade Estadual do Ceará (UECE); Professora da UECE, Fortaleza - Brasil; Grupo de Pesquisa Investigação em Arte, Ensino e História- IARTEH. Email: tania.franca@uece.br

(iD http://orcid.org/0000-0001-8931-6295

Recebido em: 08 de abril de 2020

Aprovado em: 06 de agosto de 2020

Publicado em: 01 de dezembro de 2020 